ISSN 0103-9954

\title{
RELAÇÃO ENTRE O TEOR ABSOLUTO E RELATIVO DE CLOROFILA EM FOLHAS DE VIMEIRO
}

\section{RELATIONSHIP BETWEEN ABSOLUTE AND RELATIVE CONTENT OF CHLOROPHYLL IN LEAVES OF OSIER}

\author{
Eduardo da Silva Daniel ${ }^{1}$ Cassandro Vidal Talamini do Amarante ${ }^{2}$ Mariuccia Schlichting de Martin ${ }^{3}$ \\ David José Miquelluti ${ }^{4}$ Mari Lucia Campos ${ }^{5}$
}

\begin{abstract}
RESUMO
Os métodos tradicionais para a quantificação de clorofilas implicam na destruição das folhas, além de serem demorados e dispendiosos. Uma alternativa aos métodos destrutivos é o uso de medidores portáteis, dentre eles o SPAD 502, que mede a intensidade da cor verde das folhas, resultando no índice SPAD (Soil Plant Analysis Development). No entanto, o índice SPAD deve ser ajustado para o teor de clorofilas, conforme a espécie de interesse. O objetivo do presente trabalho foi calibrar o índice SPAD para a quantificação de clorofilas em folhas de plantas de vime (Salix viminalis). Folhas desta espécie, com tonalidade variando de verde-amarelada (clorótica) a verde-escura, foram avaliadas individualmente com o SPAD-502, seguido de quantificações destrutivas dos teores de clorofilas $a, b$ e totais, expressos em unidade de área e massa fresca foliar. Houve elevado coeficiente de determinação $\left(\mathrm{R}^{2}\right)$ entre os valores de índice SPAD e os teores de clorofila $a, b$ e totais nas folhas, expressos em $\mu \mathrm{g} \mathrm{cm}^{-2}$ de área foliar $\left(\mathrm{R}^{2} \mathrm{de} 0,86 ; 0,88 \mathrm{e} 0,93\right.$, respectivamente) e entre os valores de índice SPAD e os teores de clorofilas $b$ e totais, expressos em $\mu \mathrm{g} \mathrm{g}^{-1}$ de massa fresca ( $\mathrm{R}^{2}$ 0,79 e 0,81 , respectivamente). Os resultados mostram que existe viabilidade no uso do clorofilômetro SPAD 502, como alternativa aos métodos destrutivos, para a quantificação de clorofilas (em unidade de área; $\mu \mathrm{g} \mathrm{cm}^{-2}$ ) em folhas de vimeiro.
\end{abstract}

Palavras-chave: Salix viminalis; cor da folha; propriedades óticas da folha; absorbância.

\begin{abstract}
The traditional methods for chlorophylls quantification in leaves are destructive, time consuming and expensive. One alternative to the destructive methods involve the use portable devices, such as the chlorophyll meter SPAD-502, which measure the green color intensity of the leaves, by providing the SPAD (Soil Plant Analysis Development) index. However, the SPAD index must be adjusted to the chlorophylls content in the leaves of concerned specie. The objective of this work was to calibrate the SPAD index to quantify the chlorophylls content in leaves of osier (Salix viminalis). Leaves with colors ranging from yellow-green (chlorotic) to dark green were individually assessed with the SPAD-502 and, thereafter, destructively assessed for contents of chlorophylls $a, b$ and total, expressed in terms of area and fresh mass of the leaves. There was a high determination coefficient $\left(\mathrm{R}^{2}\right)$ between the SPAD index and the contents of chlorophylls $a, b$ and total in the leaf, expressed in $\mu \mathrm{g} \mathrm{cm}^{-2}$ of leaf area $\left(\mathrm{R}^{2}\right.$ of $0.86,0.88$ and 0.93 ,

1 Engenheiro Agrônomo, MSc, Doutorando em Ciência do Solo, Universidade Estadual de Santa Catarina, Av. Luiz de Camões, 2090, CEP 88520-000, Lages (SC). edudaniel@hotmail.com

2 Engenheiro Agrônomo, PhD., Professor Associado do Departamento de Agronomia, Universidade Estadual de Santa Catarina, Av. Luiz de Camões, 2090, CEP 88520-000, Lages (SC). amarante@cav.udesc.br

3 Engenheira Agrônoma, Dra ${ }^{\mathrm{a}}$, Pesquisadora em Fisiologia Vegetal, Estação Experimental de Caçador, Empresa de Pesquisa Agropecuária e Extensão Rural de Santa Catarina, Rua Abilio Franco, 1500, CEP 89500-000, Caçador (SC).mariucciamartin@epagri.sc.gov.br

4 Engenheiro Agrônomo, Dr., Professor Associado VII do Departamento de Solos e Recursos Naturais, Universidade Estadual de Santa Catarina, Av. Luiz de Camões, 2090, CEP 88520-000, Lages (SC).dmiquell@cav.udesc.br

5 Engenheira Agrônoma, Dr ${ }^{\mathrm{a}}$., Professora Associada II do Departamento de Solos e Recursos Naturais, Universidade Estadual de Santa Catarina, Av. Luiz de Camões, 2090, CEP 88520-000, Lages (SC).mari.lucia03@gmail.com
\end{abstract}

Recebido para publicação em 23/04/2013 e aceito em 11/11/2013

Ci. Fl., v. 26, n. 1, jan.-mar., 2016 
respectively) and of between the SPAD index and the contents of chlorophylls $a$ and total, expressed in $\mu \mathrm{g} \mathrm{g}^{-1}$ fresh weight ( $\mathrm{R}^{2}$ of 0.81 and 0.79 , respectively). The results show the chlorophyll meter SPAD-502 is a suitable alternative to the destructive method to quantify chlorophylls (in area basis; $\mu \mathrm{g} \mathrm{cm}^{-2}$ ) in leaves of osier.

Keywords: Salix viminalis; leaf color; leaf optical properties; absorbance.

\section{INTRODUÇÃO}

As clorofilas são pigmentos responsáveis pela captura de luz usada na fotossíntese, sendo elas essenciais na conversão da radiação luminosa em energia química, na forma de ATP e NADPH. Assim, as clorofilas estão relacionadas com a eficiência fotossintética das plantas e, consequentemente, com seu crescimento e adaptabilidade aos diferentes ambientes (JESUS e MARENCO, 2008). Portanto, a sua quantificação é relevante no estudo de práticas culturais e de manejo visando aumentar o potencial fotossintético e de rendimento em espécies vegetais.

Tradicionalmente, os métodos utilizados para determinação do teor de clorofila requerem destruição das folhas, o que é uma desvantagem em estudos que visem determinar o efeito da ontogenia no grau de coloração verde da folha. Além disso, esses métodos são demorados e onerosos. Isto torna necessário o desenvolvimento de procedimentos práticos, de baixo custo, que permitam a quantificação dos teores de clorofila da folha de forma rápida, precisa e não destrutiva (SALLA; RODRIGUES; MARENCO, 2007).

Com o advento dos medidores portáteis, que utilizam princípios ópticos não destrutivos, baseados na absorbância e/ou refletância da luz pelas folhas, a determinação de clorofilas tornou-se fácil e rápida, podendo ser realizada a campo (RICHARDSON, DUIGAN, BERLYN, 2002; AMARANTE et al., 2008). Neste sentido, a determinação do teor relativo de clorofila, por meio do clorofilômetro SPAD, tem surgido como um método alternativo aos procedimentos convencionais destrutivos (SALLA; RODRIGUES; MARENCO, 2007). Para a quantificação de clorofilas por este método, a folha é presa entre uma haste flexível e outra rígida (pressionando-se a haste flexível) no momento da medição. A haste flexível emite luz, que atravessa o tecido foliar e atinge um receptor (fotodiodo de silicone) na haste rígida, que converte a luz transmitida em sinais elétricos analógicos. Por meio do conversor $\mathrm{A} / \mathrm{D}$, esses sinais são amplificados e convertidos em sinais digitais, sendo usados por um microprocessador para calcular a leitura SPAD.
A intensidade de cor verde na folha é detectada no aparelho através da quantidade de luz absorvida pela folha, nos comprimentos de onda $(\lambda)$ de $650 \mathrm{~nm}$ (vermelho) e $940 \mathrm{~nm}$ (vermelho distante próximo). A luz absorvida no $\lambda$ de $650 \mathrm{~nm}$ (pelas clorofilas, sem a interferência ocasionada pelos carotenoides) indica a quantidade de clorofilas, enquanto a quantidade absorvida próximo do $\lambda$ de $940 \mathrm{~nm}$ serve como referência interna na compensação da espessura e conteúdo de água da folha (SWIADER e MOORE, 2002).

Os modelos que descrevem a relação entre as leituras dos equipamentos portáteis não destrutivos variam para cada cultura, de acordo com as características intrínsecas a cada espécie, exigindo calibração independente com os teores de clorofila determinados destrutivamente (LEE, 1988; MARKWELL, OSTERMAN, MITCHELL, 1995; UDDLING et al., 2007). Um dos gêneros florestais mais disseminados, o Salix persistiu sendo cultivado ao longo do tempo dado os diversos usos e aplicações, com destaque para a proteção de barrancas de rio, fabricação de canoas, cangas de boi, calçados e artigos trançados de uso doméstico. É utilizado ainda em paisagismo, fabricação de brinquedos, amarração em pomares, bioenergia, fitorremediação, na fitoterapia e na terapia ocupacional (BRANDES e ARRUDA, 2006).

Sendo assim, esta pesquisa foi conduzida com o propósito de definir equações matemáticas para a estimativa dos teores de clorofilas em folhas de vime (Salix viminalis) a partir dos valores do índice SPAD.

\section{MATERIAL E MÉTODOS}

Folhas de plantas de Salix viminalis, com tonalidade variando de verde-amarelada (clorótica) a verde-escura, foram obtidas para a análise. A coleta ocorreu em janeiro de 2013, tendo sido procedida nos ramos rebrotados, seis meses após a poda drástica das plantas adultas, na estação experimental da EPAGRI de Lages - SC. Para a coleta, foram consideradas folhas totalmente expandidas, retiradas do terço médio das plantas, no período 
entre $8 \mathrm{~h}$ e $10 \mathrm{~h} 30 \mathrm{~min}$ da manhã (com temperatura de $18-25^{\circ} \mathrm{C}$ e umidade relativa de $70-80 \%$ ), executando imediatamente o transporte para o laboratório, com o pecíolo imerso em água destilada, para que assim se evitasse a desidratação das folhas. Em seguida, foram tomadas leituras das folhas com o medidor portátil de clorofila SPAD-502 (Konica Minolta ${ }^{\circledR}$, Tóquio, Japão), e os resultados, em índice SPAD, foram agrupados em intervalos de classe. De cada classe, foram selecionadas cinco folhas, constituindo assim uma amostra composta por classe. As leituras, em cada folha, foram procedidas na face adaxial, em número de duas para cada porção: base, porção média e ápice. Para cada classe foram realizadas três repetições.

Para a extração de clorofila, o método utilizado foi adaptado daquele descrito por Passos (1996). Nas folhas em que foram feitas as leituras com o SPAD-502, foram removidos o pecíolo e a nervura central, com o auxílio de um bisturi. De cada amostra, $1 \mathrm{~g}$ de massa fresca foi obtida em balança analítica com precisão de $0,0001 \mathrm{~g}$. Antes da extração, a área total da amostra foi determinada através de um integrador de área foliar LI-3050A (LI-COR ${ }^{\circledR}$, Lincoln, EUA). Logo após, o material vegetal foi imediatamente macerado em almofariz de porcelana contendo $5 \mathrm{~mL}$ do extrator acetona $80 \%$, juntamente com $0,5 \mathrm{~g}$ de $\mathrm{MgCO}_{3}$ (agente tamponante) e $0,5 \mathrm{~g}$ de quartzo inerte (para facilitar a maceração), em ambiente escuro Com a amostra totalmente macerada, mais $5 \mathrm{~mL}$ do extrator foram adicionados ao almofariz, filtrando-se o extrato obtido em papel-filtro rápido $n^{\circ} 42$, com o auxílio de um kitasato acoplado em uma bomba de vácuo, diminuindo assim o tempo de filtragem. A extração foi repetida, até o ponto em que o filtro, o almofariz e o kitasato não contivessem mais resíduo de clorofila da amostra. $\mathrm{O}$ extrato obtido foi recolhido em balão volumétrico de $25 \mathrm{~mL}$, completando-se o volume total com acetona $80 \%$. Os balões volumétricos foram embalados em papel alumínio para evitar a alteração das clorofilas pela luz. Para as leituras de absorção das amostras, os extratos foram colocados em cubetas de quartzo, e a absorbância foi medida em espectrofotômetro SPEKOL ${ }^{\circledR} 1300$ (Analytik Jena, Jena, Alemanha), nos comprimentos de onda de 645 e $663 \mathrm{~nm}$. A partir dessas leituras, determinou-se a concentração $\left(\mathrm{mg} \mathrm{cm}^{-3}\right)$ de clorofilas $a, b$ e totais nas soluções de leitura, por meio de fórmulas propostas por Arnon (1949):

Clorofila $a=12,7 *$ A663nm - 2,69*

\section{Clorofila $b=22,9 * \mathrm{~A} 645 \mathrm{~nm}-4,68 *$ \\ A663nm \\ Clorofilas totais $=20,2 * \mathrm{~A} 645 \mathrm{~nm}+8,02 *$ A663nm}

Os valores de concentração foram transformados para teores de clorofilas $a, b$ e totais nas amostras, expressos em unidade de área $\left(\mu \mathrm{g} \mathrm{cm}^{-2}\right)$ e de massa fresca $\left(\mu \mathrm{g} \mathrm{g}^{-1}\right)$.

Ao final, foram feitas análises de regressão entre as leituras obtidas com o clorofilômetro SPAD-502 e os teores de clorofilas $a, b$ e totais quantificados destrutivamente nas folhas, através da utilização do programa SAS.

\section{RESULTADOS E DISCUSSÃO}

Houve aumento nos teores de clorofilas $a, b$ e totais nas folhas, com o incremento nos valores de índice SPAD (Figura 1). Quando esses teores são analisados em relação à área foliar, são ajustados modelos lineares, com coeficientes de determinação $\left(\mathrm{R}^{2}\right)$ de 0,93 para clorofilas totais, 0,86 para a clorofila $a$ e 0,88 para a clorofila $b$. Quando o referencial passa a ser a massa fresca das folhas, os modelos ajustados também são lineares, porém, com $\mathrm{R}^{2}$ de 0,81 para as clorofilas totais, 0,49 para a clorofila $a$ e 0,79 para a clorofila $b$. Todos os modelos ajustados foram altamente significativos $(p<0,01)$.

Madeira et al. (2009), avaliando a nutrição de plantações jovens de eucalipto (Eucalyptus globulus), por análise foliar através de métodos não destrutivos, também encontraram altos valores de coeficientes de determinação entre o índice SPAD e a quantidade de clorofilas $a, b$ e totais $(0,91,0,90$ e 0,92 , respectivamente). Resultado similar foi reportado por Richardson, Duigan e Berlyn (2002), trabalhando com o SPAD-502 e índices de refletância espectral em folhas de bétula (Betula papyrifera Marsh.). Tais resultados foram obtidos para quantidades de clorofilas determinadas levando-se em consideração a área das folhas. Os altos valores de $\mathrm{R}^{2}$ dos modelos ajustados e a similaridade de valores entre esses coeficientes para as clorofilas $a, b$ e total, nessa base de medida, para ambos os trabalhos, corroboram os resultados encontrados no presente trabalho.

No entanto, em estudo de Amarante et al. (2008), para a quantificação de clorofilas em folhas de macieiras utilizando métodos ópticos não destrutivos em ambas as bases de referência (área foliar e massa fresca das folhas), os autores 

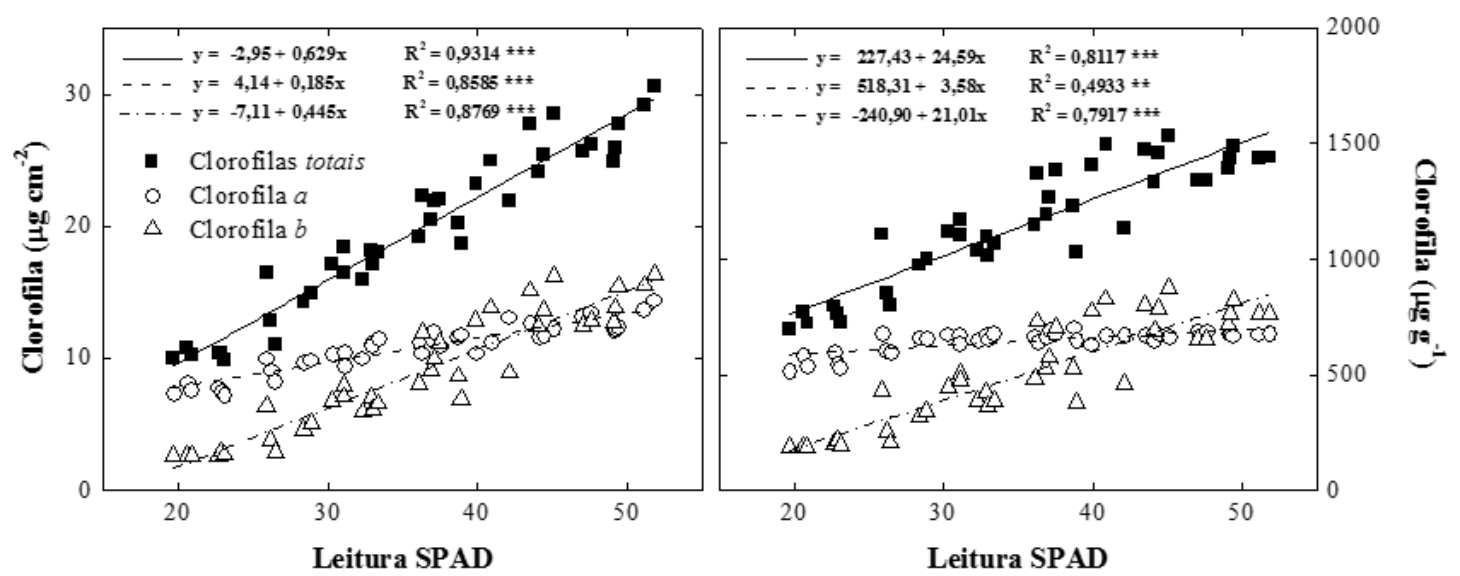

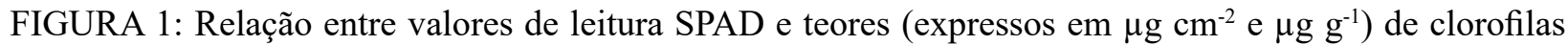
(totais, $a$ e $b$ ) em folhas de vime (Salix viminalis). ** e *** para níveis de significância, nos modelos ajustados, de 0,01 e 0,001 , respectivamente.

FIGURE 1: Relationship between the SPAD index and the contents (expresses in terms of $\mu \mathrm{g} \mathrm{cm}^{-2}$ and $\mu \mathrm{g}$ $\mathrm{g}^{-1}$ of fresh weight) of chlorophylls ( $a, b$ and total) in leaves of willow plants (Salix viminalis). $* *$ and $* * *$ for significance levels of adjusted models of 0.01 and 0.001 , respectively.

obtiveram modelos ajustados pelo índice SPAD, com diferenças expressivas de $\mathrm{R}^{2}$ entre clorofilas $a$ e total, e a clorofila $b$. Segundo esses autores, métodos não destrutivos ópticos são melhores para a estimativa dos teores de clorofilas $a$ e total do que de clorofila $b$, em macieiras. Segundo Neves et al. (2005), isto ocorre tendo em vista que o pico de absorção na faixa vermelha do espectro pela clorofila $a(663 \mathrm{~nm})$, além de ser maior que o da clorofila $b$, está muito próximo do comprimento de onda emitido pelo SPAD-502 $(650 \mathrm{~nm})$. Com isso, a maior parte da luz vermelha, emitida pelo aparelho, é absorvida pela clorofila $a$.

Esta premissa contrapõe os resultados obtidos no presente trabalho, em que os valores de $\mathrm{R}^{2}$ para os modelos ajustados para as clorofilas $b$ e total foram superiores àqueles para a clorofila $a$, quando se utilizou como base de medida $\mu \mathrm{g} \mathrm{g}^{-1}$ de massa fresca. Entretanto, há que se fazer algumas considerações. A primeira é que, quando são analisadas folhas sombreadas, o teor de clorofila $b$ é proporcionalmente maior do que o de clorofila $a$, quando comparadas com as folhas em pleno sol (TAIZ e ZIEGER, 2002). A segunda é que o SPAD-502, mesmo com sistema de compensação para alterações na espessura do mesofilo e conteúdo de água da folha (luz absorvida no $\lambda$ de $940 \mathrm{~nm}$ ), apresenta grandes variações de leitura entre espécies (CHANG, S. e CHANG, R., 1998; RICHARDSON, DUIGAN, BERLYN, 2002) e entre genótipos (NEILSEN et al., 1995; RUPP e TRANKLE, 1995; RUPP, TRANKLE e FOX, 1999; JIFON, SYVERTSEN, WHALEY, 2005), de plantas cultivadas em uma mesma condição de ambiente, devido a diferenças na estrutura e anatomia foliar. Mesmo folhas sombreadas de uma planta, apesar da menor espessura do mesófilo em relação a folhas a pleno sol, apresentam maiores valores de leituras SPAD-502, devido ao incremento na relação clorofilas $a / b$ (HOEL e SOLHAUG, 1998; MARTÍNEZ e GUIAMET, 2004). Consequentemente, os modelos ajustados entre as leituras do SPAD 502 e as quantidades de clorofilas podem apresentar maior $\mathrm{R}^{2}$ para a estimativa dos teores de clorofilas $b$ e totais do que para a clorofila $a$, como o que ocorreu no presente trabalho, quando se considera a quantidade de clorofila em $\mu \mathrm{g} \mathrm{cm}^{-2} \mathrm{e}$ $\mu \mathrm{g} \mathrm{g}^{-1}$ de massa fresca foliar.

Nos modelos lineares ajustados, nota-se um maior $\mathrm{R}^{2}$ para os teores de clorofilas nas folhas expressos em $\mu \mathrm{g} \mathrm{cm}^{-2}$, do que aqueles expressos em $\mu \mathrm{g} \mathrm{g}^{-1}$ de massa fresca. A variação que ocorre na área foliar específica, que é influenciada por diferenças na espessura do mesofilo e conteúdo de água, resulta em maior variabilidade nos valores expressos em unidade de massa fresca foliar. Portanto, a expressão dos teores de clorofilas em unidade de área deve ser preferida, quando estimada através da utilização do medidor de clorofila SPAD 502, já que resulta em menor erro (AMARANTE et al., 2008). 
É importante salientar que existem limitações associadas a diferenças quanto à espessura/anatomia foliar, influenciadas por fatores da planta e ambientais, o que justifica calibração do SPAD-502 com as extrações de clorofilas de folhas de Salix viminalis, nas condições particulares de investigação.

\section{CONCLUSÕES}

À exceção da Clorofila $a$ determinada por unidade de massa fresca, a variação da concentração de pigmentos fotossintetizantes em função do índice SPAD apresenta elevado coeficiente de determinação, revelando alta afinidade entre as duas variáveis, para folhas de plantas de Salix viminalis.

O clorofilômetro SPAD 502 apresenta maior confiabilidade quando utilizado para a quantificação dos teores de clorofilas $a, b$ e totais por unidade de área do que por unidade de massa fresca.

As clorofilas nas folhas de plantas de Salix viminalis podem ser determinadas através das seguintes equações:

$\mathrm{Y}=-2,95+0,629 \mathrm{X}$ e $\mathrm{Y}=4,14+0,185 \mathrm{X}$, em que $\mathrm{Y}$ corresponde à concentração das Clorofilas totais, em $\mu \mathrm{g} \mathrm{cm}^{-2}$ e $\mu \mathrm{g} \mathrm{g}^{-1}$, respectivamente, e X corresponde ao índice SPAD;

$\mathrm{Y}=4,14+0,185 \mathrm{X}$ e $518,81+3,58 \mathrm{X}$, em que $\mathrm{Y}$ corresponde à concentração da Clorofilas $a$, em

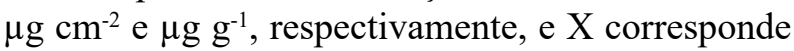
ao índice SPAD; e

$$
\mathrm{Y}=-7,11+0,445 \mathrm{X} \text { e }-240,90+21,01 \mathrm{X}
$$

em que $\mathrm{Y}$ corresponde à concentração da Clorofilas $b$, em $\mu \mathrm{g} \mathrm{cm}^{-2}$ e $\mu \mathrm{g} \mathrm{g}^{-1}$, respectivamente, e X corresponde ao índice SPAD.

\section{AGRADECIMENTOS}

Os autores agradecem à Coordenação de Aperfeiçoamento de Pessoal de Nível Superior (CAPES) e à Universidade do Estado de Santa Catarina (UDESC), pelo apoio financeiro a este trabalho.

\section{REFERÊNCIAS BIBLIOGRÁFICAS}

AMARANTE, C. V. T. et al. Quantificação de clorofilas em folhas de macieiras 'Royal Gala' e 'Fuji' com métodos ópticos não destrutivos. Revista Brasileira de Fruticultura, Jaboticabal, v.30, n.3, p.590-595, 2008.

ARNON, D.I. Copper enzymes in isolated chloroplasts: polyphenoloxydase in Beta vulgaris. Plant Physiology, Maryland, v.24, p.1-15, 1949. BRANDES, D.; ARRUDA, E. A. O cultivo do vime. 2006. Artigo em Hypertexto. Disponível em: http:// www.infobibos.com/Artigos/2006_2/Vime/index. htm. Acesso em: 22/06/2013.

CHANG, C.S.; CHANG, L.R. Two rapid determination methods for total chlorophyll content in fruit tree leaves. Bulletin of Taichung District Agricultural Improvement Station, Changhua, v.59, p.37-45, 1998.

HOEL, B.O.; SOLHAUG, K.A. Effect of irradiance on chlorophyll estimation with the Minolta SPAD502 leaf chlorophyll meter. Annals of Botany, London, v.82, n.3, p.389-392, 1998.

JESUS, S.V.; MARENCO, R.A. O SPAD-502 como alternativa para a determinação dos teores de clorofila em espécies frutíferas. Acta Amazonica, Manaus, v.38, n.4, p.815-818, 2008.

JIFON, J.L.; SYVERTSEN, J.P.; WHALEY, E. Growth environment and leaf anatomy affect nondestructive estimates of chlorophyll and nitrogen in Citrus sp leaves. Journal of the American Society for Horticultural Science, Alexandria, v.130, n.2, p.152-158, 2005.

LEE, D.W. Simulating forest shade to study the development ecology of tropical plants: Juvenile growth in three vines in India. Journal of Tropical Ecology, Cambridge, v.4, n.3, p.281-292, 1988.

MADEIRA, A. C. et al. Avaliação da nutrição de plantações jovens de eucalipto por análise foliar e métodos não destrutivos. Revista de Ciências Agrárias, Lisboa, v.32, n.2, p.139-153, 2009. MARKWELL, J.; OSTERMAN, J.C.; MITCHELL, J.L. Calibration of the Minolta SPAD-502 leaf chlorophyll meter. Photosynthesis Research, Dordrecht, v.46, n.3, p.467-472, 1995. MARTÍNEZ, D.E.; GUIAMET, J.J. Distortion of the SPAD 502 chlorophyll meter readings by changes in irradiance and leaf water status. Agronomie, Les Ulis, v.24, n.1, p.41-46, 2004.

NEILSEN, D. et al. Using SPAD-502 values to assess the nitrogen status of apple trees. Journal of the American Society for Horticultural Science, Alexandria, v.30, n.3, p.508-512, 1995.

NEVES, O.S.C. et al. Uso do SPAD-502 na avaliação dos teores foliares de clorofila, nitrogênio, enxofre, ferro e manganês do algodoeiro herbáceo. Pesquisa Agropecuária Brasileira, Brasília, v.40, n.5, p.517-521, 2005.

PASSOS, L.P. Métodos analíticos e laboratoriais em fisiologia vegetal, Brasília: Empresa Brasileira 
de Pesquisa Agropecuária - EMBRAPA, 1996. p.67-71. ISBN 85-857-4808-7.

RICHARDSON, A.D.; DUIGAN, S.P.; BERLYN, G.P. An evaluation of noninvasive methods to estimate foliar chlorophyll content. New Phytologist, Lancaster, v.153, n.1, p.185-194, 2002. RUPP, D.; TRANKLE, L. A non-destructive measurement method for chlorophyll in grapevines. Mitteilungen Klosterneuburg, Rebe und Wein, Obstbau und Fruechteverwertung, v.45, n.5/6, p.139-142, 1995.

RUPP, D.; TRANKLE, L.; FOX, R. Non-destructive measurement of chlorophyll in grapes - evaluation of varietal influences and effects of sampling methods. Mitteilungen Klosterneuburg, Rebe und Wein, Obstbau und Fruechteverwertung, v.49, n.3, p.86-92, 1999.
SALLA, L.; RODRIGUES, J.C.; MARENCO, R.A. Teores de clorofila em árvores tropicais determinados com o SPAD-502. Revista Brasileira de Biociências, Porto Alegre, v.5, n.2, p.159-161, 2007.

SWIADER, J.M.; MOORE, A. SPAD chlorophyll response to nitrogen fertilization and evaluation of nitrogen status in dryland and irrigated pumpkins. Journal of Plant Nutrition, Abingdon, v.25, n.5, p.1089-1100, 2002.

TAIZ, L.; ZEIGER, E. Fisiologia vegetal. $4^{\mathrm{a}} \mathrm{ed}$, Porto Alegre: Artmed, 2009. 819p.

UDDLING, J. et al. Evaluating the relationship between leaf chlorophyll concentration and SPAD502 chlorophyll meter readings. Photosynthesis Research, Dordrecht, v.91, n.1, p.37-46, 2007. 